\title{
Misoprostol Versus Manual Vacuum Aspiration in Treatment of Missed Miscarriage in First Trimester
}

\author{
OMLSAED M. ALMAHABRISH, M.B.B.Ch.; MOHAMED S. ABDELHAFEZ, Ph.D.; \\ MOHAMED E. TAMAN, Ph.D. and NASSER M.S. ALLAKANY, Ph.D.
}

The Department of Obstetrics \& Gynecology, Faculty of Medicine, Mansoura University

\begin{abstract}
Background: Manual vacuum aspiration (MVA) is a safe and effective technology for the treatment of missed miscarriage but it is not widely available and affordable in rural areas particularly in low resource countries. Misoprostol is an alternative to manual vacuum aspiration for the treatment of missed miscarriage.

Aim of Study: The purpose of this study was to compare the effectiveness, patient satisfaction and hematocrit drop of misoprostol versus MVA to understand the potential role of misoprostol as a first line for treatment of first trimester missed miscarriage.

Patients and Methods: A Randomized Controlled Trial was conducted from January 2020 to January 2021 at Mansoura University Maternity Hospital. Included 70 participants were randomized to treatment with either MVA or $800 \mu \mathrm{g}$ vagina misoprostol. The main outcome measures assessed at 1 week follow up were complete uterine evacuation, patient's acceptability and satisfaction.

Results: There is no statistically significant difference between studied groups regarding success rate and mean patient satisfaction score immediately and after one week, $82.9 \%$ of misoprostol group and $94.3 \%$ of MVA group successes. The mean hemoglobin and hematocrit after treatment illustrated statistically significant lower mean value among misoprostol group than MVA group (10.07 \& 10.91, respectively for $\mathrm{Hb})$ and $(30.75 \& 33$, respectively for hematocrit value). Hemoglobin drop for both groups illustrated no statistically significant difference between studied groups. There is statistically significant negative correlation between endometrial thickness $/ \mathrm{mm}$ and satisfaction after one week among both group.
\end{abstract}

Conclusion: Both misoprostol and MVA had high rates of satisfaction and complete uterine evacuation, which could ultimately reduce maternal complications from abortion. Medical treatment is as effective as surgical treatment of first trimester missed miscarriages.

Recommendations: Although misoprostol is a very effective drug, the health care professional should have thorough knowledge of the dose, side effects, complications and con-

Correspondence to: Dr. Omlsaed M. Almahabrish The Department of Obstetrics \& Gynecology, Faculty of Medicine, Mansoura University traindications before prescribing it. More studies with larger sample size are needed to elucidate the optimal method for missed miscarriage management and patient satisfaction.

Key Words: Misoprostol - Manual vacuum aspiration - First trimester missed miscarriage.

\section{Introduction}

MISCARRIAGE is the termination of pregnancy before the fetus has attained viability [1]. Approximately $11-15 \%$ of pregnancies end in spontaneous first trimester miscarriage. Therefore, safe and legal abortion is considered a key intervention for improving women's health and quality of life [2] For decades, the traditional management of incomplete miscarriage has always been surgical evacuation; the reason for many is determined by tradition, custom and habit rather than evidence-based. Risk of anesthesia with added risk of uterine perforation, intrauterine adhesions, cervical trauma and infections leading to: Infertility, pelvic pain, dyspareunia and increased risks of ectopic pregnancy [3] .

Medical methods for induced abortion have emerged over the past two decades as safe, effective, and feasible alternatives to surgery. Nonsurgical alternatives expand a woman's treatment options and, in turn, the quality of care [4]. Misoprostol as it is cheap and stable at room temperature; it has been shown to be effective for first trimester termination of pregnancy [5].

The high efficacy, safety and acceptability of misoprostol indicate that it is analogous to surgery as a first-line treatment for incomplete abortion. Misoprostol might improve post-abortion care [6]

\section{Patients and Methods}

We conducted a randomized controlled trial of 70 patients were recruited from those attending 
the outpatient clinic and emergency room of Mansoura university Hospital with missed miscarriage less than or equal to 12 weeks of pregnancy. Patients were enrolled in this study to investigate the potential role of misoprostol as a first line for treatment of first trimester missed miscarriage.

\section{Ethical considerations:}

The study protocol was approved by the Local Ethical Committee of Faculty of Medicine, Mansoura University. An informed written consent was taken from all patients and their husbands before starting the study and every patient had the right to leave the study at any time.

All participants were subjected to the following: (A) Careful history taking, including demographic data like age and parity. Medical history of any cardiovascular or thromboembolic disease, or use of IUCD. Gestational age was determined from last menstrual period or previous ultrasound scanning report. (B) Physical examination; General examination including: pulse, blood pressure, temperature, body weight, auscultation of lungs and heart. Abdominal examination: for previous scar. Pelvic examination: for evaluation of cervical motion tenderness for possibility of ectopic pregnancy. (C) Investigation: Baseline Hemoglobin, hematocrit level, were reported for every patient. Ultrasonography to confirm gestational age and exclude ectopic or other pelvic pathology. Questionnaire for patient satisfaction was performed.

\section{Inclusion criteria:}

Include: 1 - All women $>18$ years of age. 2Gestational age $\leq 12$ weeks. 3- Confirmed diagnosis of missed abortion by TV scan.

\section{Exclusion criteria:}

Include: 1- Hemodynamically unstable cases. 2- Suspected sepsis with temperature $38^{\circ} \mathrm{C}$. 3 Concurrent medical illness e.g. hematological, cardiovascular, thromboembolism respiratory illnesses, recent liver disease or pruritus of pregnancy. 4- Presence of intrauterine contraceptive device (IUCD). 5- Suspect or proven ectopic pregnancy. 6- Failed medical or surgical evacuation before presentation. 7- Known allergy to misoprostol. 8Patients who refused to participate in the study.

A total of 70 consenting eligible women were randomized into two equal groups (ratio of 1:1), namely, the misoprostol group (A) and the MVA group (B). A statistician blinded to the study's objectives generated the allocation sequence by simple randomization using Computer random sequence generator. The allocation concealment was achieved by placing the allocation in sequentially numbered, opaque, sealed identical envelopes. The envelopes were secured and placed in the gynecological emergency ward from where they were drawn serially, by a nurse.

After obtaining written informed consent from an eligible woman, she was assigned a sequential number by the investigator who then called the nurse (keeping the envelopes) to open the corresponding envelope and assign the participant to the study group (A or B) indicated on the allocation paper in the envelope. Neither the clients nor researchers were blinded to the group assignment.

\section{Statistical analysis:}

Data were statically represented in terms of range, mean. Standard deviation and percentages. Comparison between different groups in our study was done using student $t$-test for comparing parametric data, for comparing non-parametric data chi square test was performed. Correlation between various variables were done using Person correlation coefficient $(r)$ with graphic representation using linear regression line, a probability value ( $p$ value) less than 0.05 was considered significant, accuracy was represented using the terms sensitivity, specificity, positive and negative predictive values and overall accuracy.

\section{Results}

Table (1) shows a comparison of the demographic characteristics of the participants in the two study groups. The mean age of the studied groups was (29.83 \& 27.91, $p=0.228$ ), respectively, mean BMI was ( $25.3 \& 26.2, p=0.366)$ for group $\mathrm{A} \& \mathrm{~B}$, respectively. Median gravidity and parity were $(3,2, p=0.375, p=.370)$ respectively for either group. Among studied groups, $20 \%$ have medical history among group $\mathrm{A} \& \mathrm{~B}$, socio-demographic and medical history have no statistically significant difference between studied groups.

In studied groups; there is no statistically significant difference between studied groups as regard past obstetric history; $65.7 \%$ have no history of previous abortion for groups A \& B, 91.4\% of group B have no previous history of preterm labour versus $97.1 \%$ of group A. Among group A; $2.9 \%$ have preterm labour versus $8.6 \%$ of group B (Table 1).

Mean hemoglobin and hematocrit after treatment illustrates statistically significant lower mean value among group A than group B (10.07 \& 10.91 , respectively for $\mathrm{HB}, p=0.015)$ and $(30.75 \& 33$, $p=0.02$ ), respectively for hematocrit value. Mean 
hemoglobin and hematocrit drop for group A\&B illustrates no statistically significant difference between studied groups $(0.8 \& 0.7, p=0.14)$ respectively for $\mathrm{Hb}$ drop and $(2.4 \& 2.2, p=0.24)$ respectively for hematocrit drop (Table 2).

Table (1): Socio-demographic and obstetric history distribution among studied groups.

\begin{tabular}{|c|c|c|c|}
\hline & $\begin{array}{c}\text { Group A } \\
\text { (misoprostol) } \\
\mathrm{N}=35\end{array}$ & $\begin{array}{c}\text { Group B } \\
\text { (MVA) } \\
\mathrm{N}=35\end{array}$ & $\begin{array}{c}\text { Test of } \\
\text { significance }\end{array}$ \\
\hline Age/years \pm SD & $29.83 \pm 6.78$ & $27.91 \pm 6.38$ & $\begin{array}{l}t=1.22 \\
p=0.228\end{array}$ \\
\hline $\mathrm{BMI}\left(\mathrm{Kg} / \mathrm{m}^{2}\right) \pm \mathrm{SD}$ & $25.30 \pm 3.42$ & $26.20 \pm 4.72$ & $\begin{array}{l}t=0.910 \\
p=0.366\end{array}$ \\
\hline $\begin{array}{l}\text { Gravidity } \\
\text { Median (range) }\end{array}$ & $3.0(1.0-10.0)$ & $3.0(1.0-8.0)$ & $\begin{array}{l}\mathrm{z}=.887 \\
p=0.375\end{array}$ \\
\hline $\begin{array}{l}\text { Parity } \\
\text { Median (range) }\end{array}$ & $2.0(0.0-5.0)$ & $2.0(0.0-4.0)$ & $\begin{array}{l}\mathrm{z}=0.897 \\
p=0.370\end{array}$ \\
\hline $\begin{array}{l}\text { Medical history: } \\
\text { NAD } \\
\text { Bronchial asthma } \\
\text { DM } \\
\text { Hypertensive } \\
\text { Hypothyrodism } \\
\text { RA }\end{array}$ & $\begin{array}{l}28(80.0) \\
1(2.9) \\
4(11.4) \\
1(2.9) \\
1(2.9) \\
0(0.0)\end{array}$ & $\begin{array}{l}28(80.0) \\
0(0.0) \\
3(8.6) \\
3(8.6) \\
0(0.0) \\
1(2.9)\end{array}$ & \\
\hline $\begin{array}{l}\text { Abortion } \\
\text { Median (range) }\end{array}$ & $0.0(0.0-7.0)$ & $0(0.0-3.0)$ & \\
\hline $\begin{array}{l}\text { No n }(\%) \\
1 \\
2 \\
\geq 3\end{array}$ & $\begin{array}{l}23(65.7) \\
8(22.9) \\
3(8.6) \\
1(2.9)\end{array}$ & $\begin{array}{l}23(65.7) \\
9(25.7) \\
2(5.7) \\
1(2.9)\end{array}$ & $\begin{array}{l}\mathrm{MC} \\
p=0.968\end{array}$ \\
\hline $\begin{array}{l}\text { Preterm labour: } \\
\text { No } \\
1 \\
2\end{array}$ & $\begin{array}{l}34(97.1) \\
0(0.0) \\
1(2.9)\end{array}$ & $\begin{array}{l}32(91.4) \\
2(5.7) \\
1(2.9)\end{array}$ & $\begin{array}{l}\mathrm{MC} \\
p=0.357\end{array}$ \\
\hline Still birth n (\%) & $20(00-40)$ & $\begin{array}{l}1(2.9) \\
0(0.0-5.0)\end{array}$ & $\begin{array}{l}\text { FET } \\
p=1.0\end{array}$ \\
\hline $\begin{array}{l}\text { No n }(\%) \\
1 \\
2 \\
3 \\
4\end{array}$ & $\begin{array}{l}9(31.0) \\
5(17.2) \\
8(27.6) \\
5(17.2) \\
2(6.9)\end{array}$ & $\begin{array}{l}10(31.2) \\
12(37.5) \\
8(25.0) \\
1(3.1) \\
1(3.1)\end{array}$ & $\begin{array}{l}\mathrm{MC} \\
p=0.214\end{array}$ \\
\hline $\begin{array}{l}\text { Vaginal delivery } \\
\text { Median (range) }\end{array}$ & 1.0 & 0.0 & \\
\hline $\begin{array}{l}\text { No n }(\%) \\
1 \\
2 \\
3 \\
4 \\
5\end{array}$ & $\begin{array}{l}20(69.0) \\
1(3.4) \\
2(6.9) \\
2(6.9) \\
3(10.3) \\
1(3.4)\end{array}$ & $\begin{array}{l}19(59.4) \\
6(18.8) \\
2(6.2) \\
3(9.4) \\
2(6.2) \\
0(0.0)\end{array}$ & $\begin{array}{l}\mathrm{MC} \\
p=0.433\end{array}$ \\
\hline
\end{tabular}

SD : Standard deviation.

NAD : No Abnormal detected.

DM : Diabetes Mellitus.

RA : Rheumatic Arthritis.

BMI : Body Mass Index.

CS : Caesarian section.

MC : Monte Carlo test.
Table (2): Estimated drop of $\mathrm{Hb} \&$ hematocrit before and after technique among studied groups.

\begin{tabular}{lccl}
\hline & $\begin{array}{c}\text { Group A } \\
(\mathrm{N}=35)\end{array}$ & $\begin{array}{c}\text { Group B } \\
(\mathrm{N}=35)\end{array}$ & \\
\hline Hb before $\pm \mathrm{SD}$ & $10.87 \pm 1.28$ & $11.61 \pm 1.19$ & $\begin{array}{l}t=2.49 \\
p=0.015^{*}\end{array}$ \\
Hb after \pm SD & $10.07 \pm 1.42$ & $10.91 \pm 1.35$ & $\begin{array}{l}t=2.55 \\
p=0.013^{*}\end{array}$ \\
Hb drop \pm SD & $0.797 \pm 0.36$ & $0.677 \pm 0.302$ & $\begin{array}{l}t=1.50 \\
p=0.138\end{array}$ \\
HCT before $\pm \mathrm{SD}$ & $33.17 \pm 3.59$ & $35.18 \pm 3.60$ & $\begin{array}{l}t=2.34 \\
p=0.02^{*}\end{array}$ \\
HCT after $\pm \mathrm{SD}$ & $30.75 \pm 4.04$ & $33.0 \pm 3.97$ & $\begin{array}{l}t=2.35 \\
p=0.02^{*}\end{array}$ \\
& & & $t=1.18$ \\
HCT drop $\pm \mathrm{SD}$ & $2.43 \pm 1.11$ & $2.15 \pm 0.87$ & $p=0.244$ \\
& & &
\end{tabular}

*Statistically significant if $p<0.05$.

Hb: Haemoglobin. HCT: Haematocrit

Outcome distribution among studied groups demonstrates that there is no statistically significant difference between studied groups regarding success rate and mean patient satisfaction score immediately and after one week, $82.9 \%$ of group A and $94.3 \%$ of group B successes (Table 3, Figs. $1,2)$.

Table (3): Clinical outcomes of the study groups.

\begin{tabular}{lcccc}
\hline & $\begin{array}{c}\text { Group A } \\
(\mathrm{N}=35)\end{array}$ & $\begin{array}{c}\text { Group B } \\
(\mathrm{N}=35)\end{array}$ & $\begin{array}{c}\text { Test of } \\
\text { significance }\end{array}$ \\
\hline Success rate & $29(82.9)$ & $33(94.3)$ & $\chi^{2}=2.26$ & $p=0.133$ \\
$\begin{array}{c}\text { Patient Satisfaction } \\
\text { immediately } \pm \text { SD }\end{array}$ & $4.17 \pm 0.71$ & $3.91 \pm 0.91$ & $t=1.31$ & $p=0.194$ \\
$\begin{array}{c}\text { Patient Satisfaction } \\
\text { after one week } \pm \text { SD }\end{array}$ & $4.26 \pm 0.95$ & $4.17 \pm 0.79$ & $t=0.411$ & $p=0.682$ \\
\hline
\end{tabular}

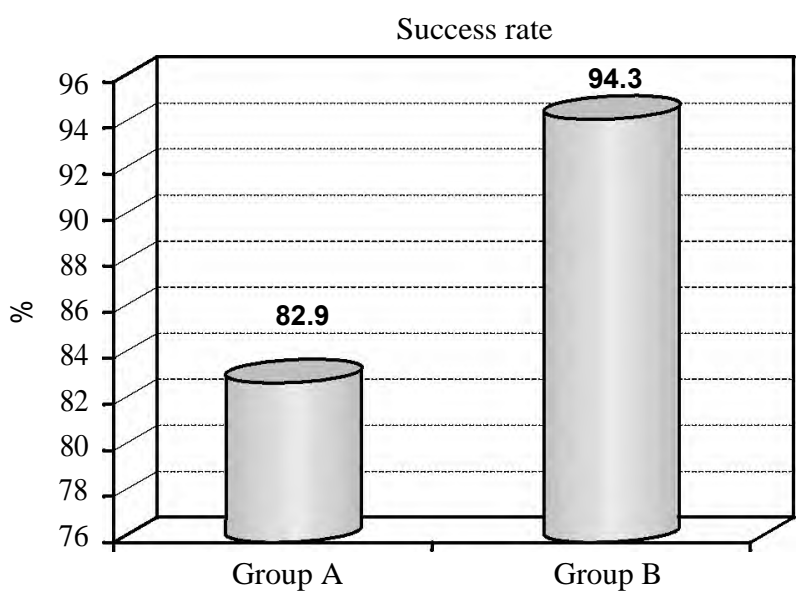

Fig. (1): Success rate distribution among studied groups. Group A (misoprostol group); Group B (MVA group). 

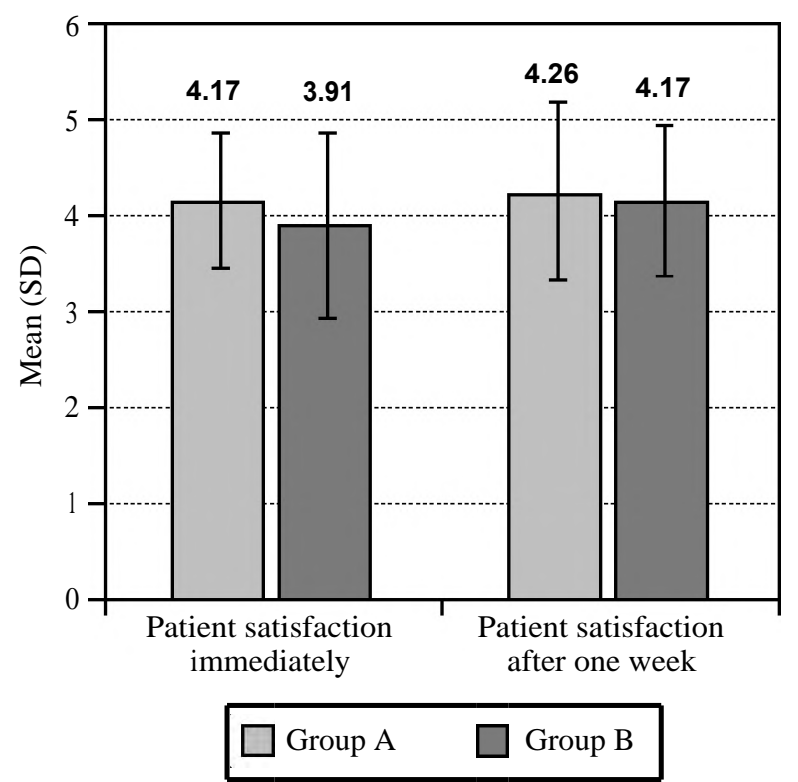

Fig. (2): Satisfaction distribution among studied groups. Group A (misoprostol group); Group B (MVA group).

In group A, $74.3 \%$ of the studied females were accidently discovered versus $54.7 \%$ of group B without significant difference between them. Mean gestational age at delivery was 8.57 weeks among group A versus 9.31 weeks among group B without significant difference between them. Presence of fetal pole was detected among $94.3 \%$ of group A and $97.1 \%$ of group B without significant difference between groups (Table 4).

Table (4): State of current pregnancy among studied groups.

\begin{tabular}{|c|c|c|c|}
\hline & $\begin{array}{c}\text { Group A } \\
(\mathrm{N}=35)\end{array}$ & $\begin{array}{c}\text { Group B } \\
(\mathrm{N}=35)\end{array}$ & $\begin{array}{c}\text { Test of } \\
\text { significance }\end{array}$ \\
\hline \multicolumn{4}{|l|}{ Complaint n (\%) } \\
\hline Vaginal bleeding & $9 \quad(25.7)$ & $16(45.7)$ & $\chi^{2}=3.05$ \\
\hline Accidental discovered & $26(74.3)$ & $19(54.3)$ & $p=0.081$ \\
\hline $\begin{array}{l}\text { Gestational age } \\
\text { at presentation / } \\
\text { week } \pm \text { SD }\end{array}$ & $8.57 \pm 1.88$ & $9.31 \pm 1.83$ & $\begin{array}{l}t=1.69 \\
p=0.096\end{array}$ \\
\hline \multicolumn{4}{|l|}{ Fetal pole $n(\%)$ : } \\
\hline Absent & $2 \quad(5.7)$ & $1 \quad(2.9)$ & FET \\
\hline Present & $33(94.3)$ & $34(97.1)$ & $p=1.0$ \\
\hline $\begin{array}{l}\text { Gestational sac } \\
\text { (present) } \mathrm{n}(\%)\end{array}$ & $35(100)$ & $35(100)$ & \\
\hline
\end{tabular}

There is statistically significant negative correlation between endometrial thickness/mm and satisfaction after one week among group A\&B ( $r=-0.554, p=.001$ and $r=-0.413, p=0.014)$, respectively and among total $(r=-0.469, p<0.001)$ (Table 5).
Table (5): Correlation between success rate and number of CS, vaginal delivery, Satisfaction score among studied groups.

\begin{tabular}{|c|c|c|c|}
\hline GP & & & $\begin{array}{l}\text { Endometrial thickness } \\
\text { (assess success rate) }\end{array}$ \\
\hline \multirow[t]{8}{*}{ A } & Number of CS & $r$ & .195 \\
\hline & & $p$ & .310 \\
\hline & Number of vaginal deliveries & $r$ & -.163 \\
\hline & & $p$ & .399 \\
\hline & Satisfaction score immediately & $r$ & -.154 \\
\hline & & $p$ & .376 \\
\hline & Satisfaction score after one week & $r$ & $-.554 * *$ \\
\hline & & $p$ & .001 \\
\hline \multirow[t]{8}{*}{ B } & Number of CS & $r$ & .003 \\
\hline & & $p$ & .986 \\
\hline & Number of vaginal deliveries & $r$ & -.106 \\
\hline & & $p$ & .562 \\
\hline & Satisfaction score immediately & $r$ & -.324 \\
\hline & & $p$ & .058 \\
\hline & Satisfaction score after one week & $r$ & $-.413^{*}$ \\
\hline & & $p$ & .014 \\
\hline
\end{tabular}

\section{Discussion}

This randomized study indicates that medical treatment of first trimester missed miscarriages with vaginal 800 nisoprostol is as effective as MVA. In our study, the effectiveness of misoprostol for treatment of first trimester missed miscarriage was $82.9 \%$ whereas that of MVA was $94.3 \%$. The success rate observed in the misoprostol group is similar to that reported by Tasnim and colleagues in Pakistan [7], Shuaib and Alharazi in Egypt [8], Shaheen and colleagues in Pakistan [9] and Tahir and Aamir [10]. Similarly, Verma and colleagues [11]; Ibiyemi and colleagues [12]; Abdulmajeed and colleagues [13] found that success rate was in the range of $83-97 \%$ in misoprostol group and $95-99 \%$ in MVA group, our results were comparable with these studies. The high success rate observed in the misoprostol group suggests that the medical management of missed abortion in a well selected patient is an effective alternative to MVA.

Lower gestational age was significantly associated with success rate (increased gestational age decrease success rate). Our finding agree with another study showed that the lower gestational age the higher success rate of misoprostol [14].

We found that there is no statistically significant difference between studied groups related to success rate and mean patient satisfaction score immediately and after one week (Table 3), $82.9 \%$ of group A and $94.3 \%$ of group B success. While in other study by Nwafor and colleagues [15] contradicts 
our findings as the authors showed that the mean client satisfaction score was significantly higher among women in the misoprostol arm compared to participants in MVA group.

After assessment of blood loss we found that mean hemoglobin and hematocrit after treatment illustrates statistically significant lower mean value among misoprostol group than MVA group (10.07 $\& 10.91$, respectively for $\mathrm{Hb})$ and $(30.75 \& 33$, respectively for hematocrit value). Hemoglobin drop for both groups illustrates no statistically significant difference between studied groups. Ahmed and colleagues [16] agree our findings while in another study by Nwafor and colleagues [15] there was no significant difference in both pretreatment and post-treatment mean hemoglobin concentration in both study groups.

In our study, mean age of patients which observed in misoprostol group was 29.83 years, whereas in MVA group was 27.91 years. Median parity was 2 and median gravidity was 3 (Table 1). Ahmed and colleagues [16] found that mean age in misoprostol group was 27.82 years while in MVA group mean age was 27.15 years. Mean parity was $1.67 \pm 1.44 \mathrm{SD}$ in misoprostol group while mean parity was $1.46 \pm 1.47$ SD in MVA group; their results were slightly lower than the current results. In our study, only $20 \%$ have medical history in both groups ( $\mathrm{A}$ and $\mathrm{B}$ ) like bronchial asthma, DM, hypertension, hypothyroidism and RA.

In our study, mean gestational age at abortion was 8.57 weeks in misoprostol group versus 9.31 weeks in MVA group without significant difference between them (Table 4). The mean gestational age in our study population was slightly higher than what was found in another study in Nigeria found that mean gestational age in misoprostol and MVA groups were 8.13 and 8.17 weeks, respectively [12].

There is statistically significant negative correlation between endometrial thickness/mm and satisfaction after one week among group $\mathrm{A} \& \mathrm{~B}$ $(r=-0.554$ and $r=-0.413$, respectively) and among total ( $r=-0.469)$ (Table 5). These results came in harmony with Abdulmajeed and colleagues [13] where they stated that before treatment, the mean of endometrial thickness was $22.1 \mathrm{~mm}$ and $21.9 \mathrm{~mm}$ in MVA and misoprostol groups, respectively. The difference between the studied groups was statistically non-significant $(p>0.05)$. After treatment the difference in the mean of endometrial thickness between the studied groups was statistically nonsignificant $(p>0.05)$.
The differences in success rates and misoprostol dose requirements between studies can be due to a number of factors, including the route of administration, different dose patterns, repeat dose patterns, extending the follow-up period (waiting for 3-15 days was found to be associated with higher success rates), patient selection, and the type of PG analogue used, small sample size causing bias, use of USG before starting treatment is associated with higher success, criteria used to define success.

Conclusion: Medical treatment is as effective as surgical treatment of first trimester missed miscarriages. Misoprostol could be recommended as the standard of care for well motivated women with uncomplicated first trimester missed miscarriages while the MVA use be limited to women with complications and those unlikely to adhere to follow-up to confirm complete uterine evacuation.

Recommendations: More studies with larger sample size are needed to elucidate the optimal method for missed miscarriage management and patient satisfaction.

\section{References}

1- KAILASH T. and PARBATI T.: Use of miferistone and misoprostol combination on abortion in first trimester pregnancy at Government Hospital in Chitwan District in Nepal. Int. Res. J. Pharm, 6 (6): 359-64, 2015.

2- SHOKRY M., FATHALLA M., HUSSIEN M. and EISSA A. A.: Vaginal misoprostol versus vaginal surgical evacuation of first trimester incomplete abortion: Comparative study. Middle East Fertility Society Journal, 19 (2): 96101,2014

3- PANDEY A., KUNDU S. and DESHMUKH P.Y.: A comparison of intravaginal misoprostol with sublingual misoprostol for second trimester medical termination of pregnancy. International Journal of Reproduction, Contraception, Obstetrics and Gynecology, 4 (2): 403-7, 2015.

4- GUILLAUME A., ROSSIER C. and REEVE P.: Abortion around the world. An overview of legislation, measures, trends, and consequences. Population, 73 (2): 217-306, 2018.

5- PATIL E. and EDELMAN A.: Medical abortion: use of mifepristone and misoprostol in first and second trimesters of pregnancy. Current Obstetrics and Gynecology Reports, 4 (1): 69-78, 2015.

6- DABASH R., RAMADAN M.C., DARWISH E., HASSANEIN N., BLUM J. and WINIKOFF B.: A randomized controlled trial of 400- g g blingual misoprostol versus manual vacuum aspiration for the treatment of incomplete abortion in two Egyptian hospitals. International Journal of Gynecology \& Obstetrics, 111 (2): 131-5, 2010.

7- TASNIM N., MAHMUD G., FATIMA S. and SULTANA M.: Manual vacuum aspiration: A safe and cost effective substitute of Electric vacuum aspiration for the surgical 
management of early pregnancy loss. Journal of the Pakistan Medical Association, 61 (2): 149-53, 2011.

8- SHUAIB A.A. and ALHARAZI A.H.: Medical versus surgical termination of the first trimester missed miscarriage. Alexandria Journal of Medicine, 49 (1): 13-6, 2013

9- SHAHEEN H., KHOSA M.S. and HANIF H.: Comparison of Efficacy of Manual Vacuum Aspiration (MVA) and Medical Treatment in the Management of First Trimester Missed Miscarriage. Pakistan Journal of Medical \& Health Sciences, 11 (1): 270-3, 2017.

10- TAHIR A. and AAMIR F.: To compare the efficacy of manual vacuum aspiration verses misoprostol in first trimester incomplete miscarriage. Pakistan Journal of Surgery, 34 (3): 250-4, 2018.

11- VERMA M., THAKUR V. and AWASIYA P.: A comparative study of misoprostol versus surgical management of incomplete and missed miscarriage. Int. J. Reprod Contracept Obstet. Gynecol., 5 (11): 3654-8, 2016.

12- Ibiyemi K.F., Munir'deen A.I. and Adesina K.T.: Randomised trial of oral misoprostol versus manual vacuum aspiration for the treatment of incomplete abortion at a
Nigerian Tertiary Hospital. Sultan Qaboos University Medical Journal, 19 (1): 38-43, 2019.

13- ABDULMAJEED A.M., HUSSEIN H.E., ELDESOUKY E. and FARAG E.: Comparison between Medical and Surgical Treatment of Incomplete First Trimester Abortion. Life Sci., 16 (8): 1-10, 2019.

14- ELkholi D.G.E. and Hefeda M.M.: Potential predictors for successful misoprostol treatment for early pregnancy failure: Clinical and color Doppler imaging study. Middle East Fertility Society Journal, 20 (3): 144-53, 2015.

15-NWAFOR J.I., AGWU U.M., EGBUJI C.C. and EKWEDIGWE K.C.: Misoprostol versus Manual Vacuum Aspiration for Treatment of First Trimester Incomplete Miscarriage in a Low Resource Setting: A Randomized Controlled Trial. Nigerian Journal of Clinical Practice, 23 (5): 63846, 2020.

16- AHMED S.K.: Comparison of Sublingual Misoprostol and Manual Vacuum Aspiration for the Treatment of Incomplete Abortion in First Trimester in Terms of Frequency of Decreased Haemoglobin Levels. Journal of Rawalpindi Medical College, 21 (3): 208-10, 2017.

\title{
المقارنة بين استخدام عقار الميسوبروستول

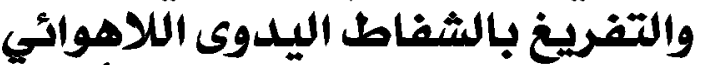

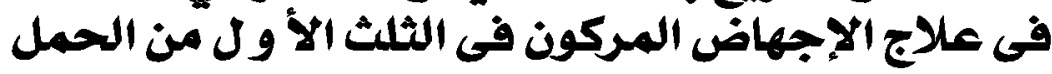

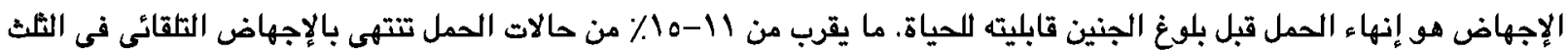

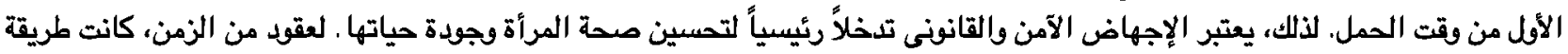

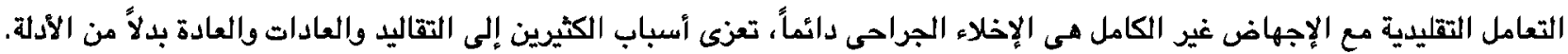

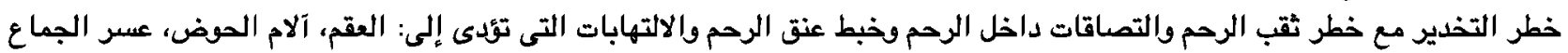

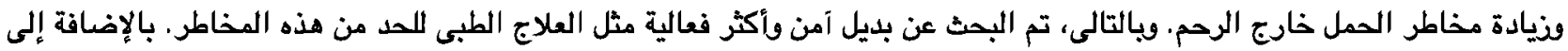 \\ ذلك، يتطلب الإخلاء الجراحى رعاية المرضى، مما يزيد من تكلفة الرعاية الصحية حتى فلو لفترة تصيرة.

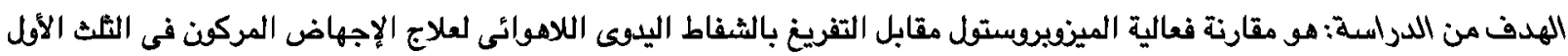

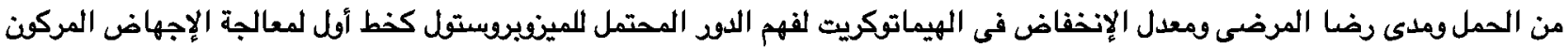

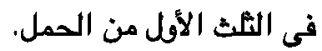

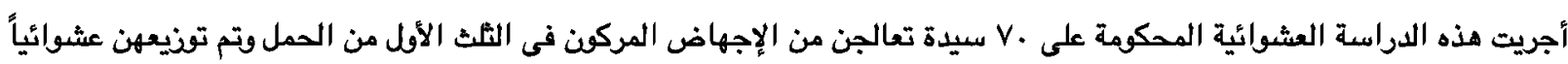

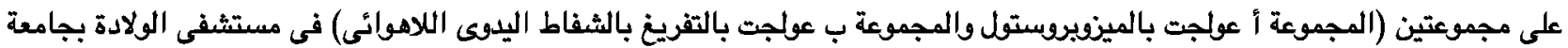

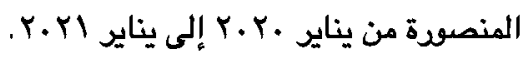 \\ وقد خلصت الدراسة إلى أن استخدام العلاج الطبى فعال مثل العلاج الجراحى لحالات الإجهاض المركون فى الثلث الأول من الحمل.
}

